\title{
Contextual conditioning with an illness US is attenuated by the antiemetic ondansetron
}

\author{
MICHELLE SYMONDS and GEOFFREY HALL \\ University of York, York, England
}

\begin{abstract}
In two experiments, rats received an injection of $\mathrm{LiCl}$ before being placed in a distinctive context. The formation of an aversion to the context was evident in the rats' unwillingness, on a subsequent test trial, to consume a (normally palatable) sucrose solution in that context. Experiment 1 demonstrated that the size of the context aversion was reduced in rats that received an injection of the antiemetic ondansetron, a selective $5-\mathrm{HT}_{3}$ antagonist, immediately prior to the injection of $\mathrm{LiCl}$. Experiment 2 confirmed this effect and showed it to occur also in rats that received an injection of ondansetron prior to the test trial (thus ruling out an explanation of Experiment 1 in terms of state-dependency of conditioning). The implications of these findings for the development of an animal learning model of the conditioned side effects experienced by patients undergoing cancer chemotherapy are considered.
\end{abstract}

The cytotoxic drugs (e.g., cisplatin, cyclophosphamide) used in the treatment of some forms of cancer have a range of unpleasant side effects; in particular, they can induce a state of nausea and attacks of vomiting that can be severe and protracted, lasting for several days (Andrews, Rapeport, \& Sanger, 1988). In addition to suffering this posttreatment nausea and vomiting (PNV), some patients also develop anticipatory nausea and vomiting (ANV); after a few sessions of treatment, simply being present in the clinic becomes enough to evoke nausea or vomiting, or both (see Stockhorst, Klosterhalfen, \& Steingrüber, 1998 , for a review). It has been generally accepted that ANV may have a classical conditioning etiology, in which the clinic where the treatment is given serves as the conditioned stimulus (CS), and the infusions of chemotherapeutic drugs serve as the unconditioned stimulus (US). After a number treatment sessions, or CS-US pairings, the complex of stimuli (sights, sounds, smells) that constitute the clinic (the CS) become capable of evoking a conditioned response (CR) of nausea and vomiting that is similar to the response directly evoked by the US, the chemotherapy drug (Carey \& Burish, 1988; Hall, 1997; Stockhorst, Klosterhalfen, \& Steingrüber, 1998).

This interpretation of ANV has prompted the attempt to use the standard techniques of the conditioning laboratory to develop an animal model of the phenomenon. We have investigated the effects of a procedure in which rats are given an injection of a nausea-inducing agent ( $\mathrm{LiCl}$ in our studies) immediately before being placed in a distinctive context. This training appears to endow the context with aversive properties, as assessed by a reduction in the willingness of the rats to consume an otherwise palat-

This work was supported by a grant from the Wellcome Trust. We thank C. Bonardi and C. Mitchell for helpful discussion. Correspondence concerning this article should be sent to G. Hall, Department of Psychology, University of York, York, YO10 5DD, England (e-mail: ghl@ york.ac.uk). able fluid in the presence of the contextual cues (Rodríguez, López, Symonds, \& Hall, 1999). Further development of this procedure as a model of ANV requires the demonstration that the measure that we use reflects a state of conditioned sickness or nausea akin to that thought to be characteristic of ANV in the clinic. One line of evidence to support this conclusion comes from the observation (e.g., Domjan, 1977) that a suppression of the rat's willingness to consume a novel flavor is a direct, immediate effect of a $\mathrm{LiCl}$ injection. The finding that contextual cues can come to elicit the same sort of response is thus consistent with the suggestion that these cues come to evoke the same state as that evoked by the injection itself. In the experiments to be reported here, we investigated the effects of antiemetic drugs on context aversion in an attempt to supply a further line of relevant evidence.

$\mathrm{LiCl}$ (in common with the cytotoxic drugs used in chemotherapy; see, e.g., Parker, 1998) will readily support the acquisition of a conditioned taste aversion, a CR that has commonly been supposed to reflect the ability of the taste to evoke a state of conditioned sickness. It is possible, however, to interpret conditioned taste aversions as being the consequence solely of a conditioned shift in the palatability of the taste without the need to suppose that the taste comes to evoke a state of nausea (see Garcia, Hankins, \& Rusiniak, 1974). One strategy for addressing this issue has been to make use of antiemetic drugs. Given that such drugs are known to suppress nausea in humans, the demonstration that they can prevent the development of a taste aversion if given during conditioning, or prevent its expression if given on test, would provide evidence that the state of nausea plays an important role in taste aversion learning. The results of such experiments have been mixed. Some (e.g., Goudie, Stolerman, Demellweek, \& D'Mello, 1982; Mele, McDonough, McLean, \& O'Halloran, 1992; Rudd, Ngan, \& Wai, 1998) have found antiemetics to be without effect on conditioned taste aversions, whereas others have found them to attenuate both the acquisition 
Table 1 Experimental Designs

\begin{tabular}{|c|c|c|}
\hline Group & Training & Test \\
\hline \multicolumn{3}{|c|}{ Experiment 1} \\
\hline$A+$ Ond & $\begin{array}{c}\text { Ond-Li-A } \\
\quad \& \\
\text { Veh-0-B }\end{array}$ & $\begin{array}{l}\text { Sucrose in A } \\
\text { Sucrose in B }\end{array}$ \\
\hline$A+V e h$ & $\begin{array}{c}\text { Veh-Li-A } \\
\& \\
\text { Ond } / 0-\mathrm{B}\end{array}$ & $\begin{array}{l}\text { Sucrose in A } \\
\text { Sucrose in B }\end{array}$ \\
\hline \multicolumn{3}{|c|}{ Experiment 2} \\
\hline & $\begin{array}{c}\text { Ond-Li-A } \\
\& \\
\text { Veh-Li-B }\end{array}$ & $\begin{array}{l}\text { Ond-A \& Veh-B } \\
\text { Veh-A \& Ond-B }\end{array}$ \\
\hline
\end{tabular}

Note $-A$ and $B$ designate distinctive contexts; Ond indicates an injection of ondansetron, Veh an injection of vehicle, $\mathrm{Li}$ an injection of $\mathrm{LiCl}$, and 0 no injection. On training trials and test trials for Experiment 2, the injection of Ond or Veh was given 15 min prior to the rat's being placed in the context. The Li injection, when given, immediately preceded the animal's being placed in the context.

and the expression of the aversion (e.g., Balleine, Garner, \& Dickinson, 1995; Coil, Hankins, Jenden, \& Garcia, 1978; McAllister \& Pratt, 1998).

Although the role of nausea in conditioned taste aversion has not been resolved by these experiments, we may still attempt to apply the same logic to the analysis of conditioned context aversions. In the experiments to be reported here, we investigated whether the administration of an antiemetic drug would serve to attenuate the context aversion produced in rats by context- $\mathrm{LiCl}$ pairings. In Experiment 1, we administered the antiemetic during the initial conditioning trials in order to see whether a treatment that can be assumed to suppress the nausea induced by the $\mathrm{LiCl}$ injection would render that injection less effective as a US. To find such an effect would strengthen claims for the validity of our context conditioning procedure as an animal model of ANV - for human patients, the extent to which ANV develops is directly related to the severity of PNV produced by the cytotoxic drug treatment (e.g., Stockhorst, Klosterhalfen, Klosterhalfen, Winkelmann, \& Steingrüber, 1993; Stockhorst, Klosterhalfen, \& Steingrüber, 1998). In Experiment 2, we extended our procedure to look also at the effects produced by administering antiemetic treatment during the test trial.

\section{EXPERIMENT 1}

The procedure that we used to produce contextual conditioning in the present study was modeled directly on that described by Rodríguez et al. (1999). In their experiments, rats received training trials in which they were injected with $\mathrm{LiCl}$ immediately before being placed for $30 \mathrm{~min}$ in a distinctive (and, at the start of conditioning, novel) context. The test procedure consisted of giving the rats access to a sucrose solution in the context. It was found that the rats consumed less of the sucrose in this context than in another context that had not been paired with the $\mathrm{LiCl}$ injection. Rodriguez et al. argued that this effect can be taken to indicate that context paired with $\mathrm{LiCl}$ had acquired aversive properties. This training method differs from that commonly used previously to generate context- $\mathrm{LiCl}$ associations (it has been more usual to give experience of the context prior to, rather than after, the injection of LiCl; e.g., Best, Brown, \& Sowell, 1984; Boakes, Westbrook, \& Barnes, 1992; Symonds \& Hall, 1997). As a procedural arrangement, however, this "backward" technique maps rather well onto the conditioning situation thought to give rise to ANV. In the latter case, the patients receive the chemotherapy (and hence the nausea that it generates) in the presence of the contextual cues. Similarly, by giving the rat subjects an injection of $\mathrm{LiCl}$ prior to experience of the context, it is assumed that at least some of the direct effects of the $\mathrm{LiCl}$ will be experienced in the presence of the critical cues.

The antiemetic used in this experiment was ondansetron (GR38032F). This compound is a selective antagonist of the $5-\mathrm{HT}_{3}$ receptor. It appears to act both peripherally, on afferents from the gastrointestinal tract, and also centrally, on receptor sites in the area postrema of the medulla (Higgins, Kilpatrick, Bunce, Jones, \& Tyers, 1989). We chose this drug for two reasons. First, problems with side effects produced by the antiemetics previously employed (e.g., metoclopramide) have led to the increasing clinical use of 5- $\mathrm{HT}_{3}$-receptor antagonists in the attempt to control chemotherapy-induced emesis. Ondansetron has been very widely used and has been shown to be particularly effective in reducing the severity of PNV (Andrews et al., 1988; Chaffee \& Tankanow, 1991). It is thus of special relevance to make use of this drug in the investigation of an animal model of ANV. Second, ondansetron was the antiemetic used by Balleine et al. (1995) in the experiment in which they successfully demonstrated the attenuation of a LiCl-based taste aversion. As we have already noted, it is not clear why antiemetics should sometimes be effective in the taste conditioning procedure and sometimes not; nor is it clear that the variables that influence the effect on taste aversion would also influence context aversion. None the less it seemed sensible to begin the investigation of antiemetics and context aversion by making use of a drug that was known to be effective in the taste aversion case.

The design of the experiment is shown in the top part of Table 1. There were two groups of subjects. All received discrimination training in which experience of a target context (A) was preceded by an injection of $\mathrm{LiCl}$ and experience of a second, nontarget, context (B), was not. For subjects in the experimental condition (Group A+Ond), an injection of ondansetron was administered prior to each conditioning trial with context A; control subjects (Group A+Veh) were treated equivalently except that they received an injection only of the vehicle at this time. Half of the subjects in each group were then tested for their consumption of sucrose in context $\mathrm{A}$, and the remaining half were tested in context $B$. Our previous work with rats not given an antiemetic led us to expect that the rats from Group $A+V e h$ tested in context $A$ would be less willing to consume the sucrose than those tested in context B. But if the antiemetic properties of ondansetron served 


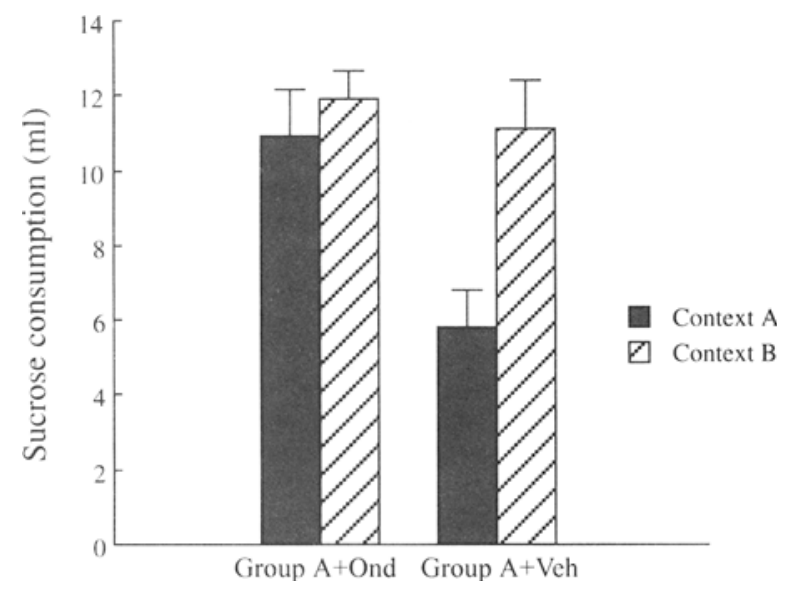

Figure 1. Experiment 1: Group means for sucrose consumption on test in contexts $A$ and $B$. Both groups had previously experienced context $A$ after an injection of LiCl. Group A+Ond received an injection of ondansetron prior to this treatment; Group $A+V e h$ received an injection of saline vehicle.

to reduce the strength of the context aversion, this difference would be attenuated for subjects in Group A+Ond; for this group we might expect to see a level of consumption in context A similar to that obtained in context $B$.

\section{Method}

Subjects and Apparatus. The subjects were 31 experimentally naive male (hooded) Lister rats with a mean free-feeding weight of $442 \mathrm{~g}$ (range: $370-530 \mathrm{~g}$ ). They were housed singly in home cages made of opaque white plastic, measuring $35 \times 22 \times 19 \mathrm{~cm}$. These had a roof of wire mesh that held food and (when available) a water bottle, and a layer of wood shavings covered the floor. The home cages were kept in a colony room that was brightly lit from 0800 to $2000 \mathrm{~h}$ each day.

Two further sets of cages, both different from the home cages and located in separate parts of the laboratory, served as the experimental contexts. One set of cages was located in a small room dimly lit by a single $60-\mathrm{W}$ red lamp. The cages were made of transparent plastic and measured $36 \times 20 \times 20 \mathrm{~cm}$. The floors of these cages were covered with commercially obtained cat litter. A speaker supplied a constant background white noise with an intensity of $75 \mathrm{~dB}$ measured next to the cages. The cages that constituted the other context were larger, measuring $42 \times 35 \times 16 \mathrm{~cm}$, and were located in a brightly lit colony room. The walls and floor of the cages were made of translucent white plastic, and the roof of wire mesh. These two sets of cages are known to be discriminably different from each other, having been used in our previous studies of context conditioning (e.g., Symonds \& Hall, 1997). Calibrated tubes equipped with stainless steel ball-bearing-tipped spouts were used to present measured quantities of a $3.4 \%$ sucrose solution in these cages during the test phase. Fluid consumption was measured by weighing the tubes before and after fluid presentation and recording to the nearest $0.5 \mathrm{~g}$.

The US for the conditioning trials was an injection of $0.3 \mathrm{M} \mathrm{LiCl}$ administered intraperitoneally at $10 \mathrm{ml} / \mathrm{kg}$ of body weight. The antiemetic ondansetron (Zofran, GlaxoWellcome) was administered subcutaneously at $0.3 \mathrm{mg} / \mathrm{kg}$ of body weight. It was dissolved in a physiological saline vehicle (to which was added a small amount of dilute sodium hydroxide in order to maintain a $\mathrm{pH}$ value of 7) at a concentration of $.1 \mathrm{mg} / \mathrm{ml}$. This dose level is somewhat higher than that employed in the study by Balleine et al. (1995) to compensate for the fact that in our experiment a more powerful US was used (Balleine et al. used .15 $\mathrm{M} \mathrm{LiCl}$ at $5 \mathrm{ml} / \mathrm{kg}$ ).

Procedure. The subjects were first introduced to a regime of water deprivation over 2 days, in which they were permitted to drink freely from the standard water bottles for two 60-min sessions each day, these sessions being initiated at $1000 \mathrm{~h}$ and $1700 \mathrm{~h}$, respectively. Unless otherwise specified, fluid continued to be given at these times throughout the remainder of the experiment. Free access to food was allowed throughout the experiment. After the initial period of water deprivation, all subjects received a 30 -min presentation of water in the calibrated drinking tubes at $1000 \mathrm{~h}$, and consumption was measured in order to establish individual baseline levels of fluid intake. The subjects were then assigned to two groups, Group A+Ond, and Group A+Veh, matched for baseline levels of fluid consumption.

The next 8 days constituted the conditioning phase. On the 1st day, all subjects received, at $1000 \mathrm{~h}$, free access to water for $60 \mathrm{~min}$. At $1300 \mathrm{~h}$, all subjects received an injection of ondansetron. Fifteen minutes later, subjects in Group A+Ond received an injection of LiCl immediately prior to being placed into the target context A where they remained for $30 \mathrm{~min}$ before being returned to their home cages. Subjects in Group A+Veh, however, received no $\mathrm{LiCl}$ injection but, $15 \mathrm{~min}$ after the injection of ondansetron, were transferred to the nontarget context (B) for $30 \mathrm{~min}$ before being returned to the home cage. At $1700 \mathrm{~h}$, the subjects were again permitted to drink water for $60 \mathrm{~min}$ in the home cage. On Day 2, all subjects received an injection of physiological saline vehicle at $1300 \mathrm{~h}$. For subjects in Group A+Ond, this injection was followed 15 min later by their being placed into the nontarget context $B$; subjects in Group $A+V e h$ received an injection of $\mathrm{LiCl}$ before being put into context $\mathrm{A}$. This 2-day cycle was then repeated a further three times. For half the subjects in each group, context A consisted of the large cages and context $B$ of the smaller cages; for the remaining animals, this arrangement was reversed.

On the day following the final conditioning day, all subjects received a test in which they were placed in a context for $15 \mathrm{~min}$ where they were permitted free access to sucrose. For this test, the groups were each divided into two further subgroups (again matched for baseline levels of water consumption), half of which received their test in the target context, A, and half of which received their test in the nontarget context, $\mathrm{B}$.

\section{Results and Discussion}

No data were recorded for the training phase. The results of the test trial-group means for consumption of sucrose-are shown in Figure 1. The left-hand panel of this figure shows the results of the test in either context A or B for subjects in Group A+Ond; the right-hand panel shows the results in each of the two contexts for subjects in Group $A+V e h$. It is clear from Figure 1 that the subjects in Group A+Veh that were tested in context A consumed less of the sucrose than those tested in context B. This replicates the finding of Rodríguez et al. (1999) and is what would be expected if context $A$ had acquired aversive properties as a result of the pairings with $\mathrm{LiCl}$ given during the conditioning phase. For animals in Group $A+$ Ond, however, subjects tested in context $A$ consumed the sucrose as readily as those tested in context B, and both subgroups showed a level of consumption closely similar to that shown by the $A+V e h$ subjects tested in the context (B) that had not been associated with $\mathrm{LiCl}$ in training. This impression of the data was confirmed by statistical analysis. A one-way analysis of variance (ANOVA) 
conducted on the data summarized in the figure showed there to be a significant difference among the groups $[F(3,27)=9.38]$. The rejection level adopted for this and all subsequent analyses was $p<.05$. Subsequent pairwise comparisons using the Newman-Keuls test confirmed that the subjects from Group A+Veh tested in context A differed from each of the other three groups, which did not differ among themselves.

These findings are consistent with the notion that antiemetic treatment (in this case ondansetron) is capable of alleviating contextually conditioned nausea in rats. Our index of such learning is the animals' tendency to show suppressed consumption of a taste in the target context, and the subjects who had received ondansetron prior to conditioning trials with context A (Group A+Ond) showed no evidence of an aversion to the context by this measure. Having received ondansetron in association with a given context was not in itself sufficient to influence the performance shown on the test- the subgroups tested in the nontarget context B did not differ in the levels of consumption that they showed, although one had received ondansetron before experiencing that context in training and the other had not. This pattern of results supports the proposal that the effective US in producing the context aversion in our training procedure is a state of nausea produced by the injection of $\mathrm{LiCl}$, and that ondansetron is able to restrict conditioning because it alleviates this state. Before we accepted this conclusion, however, an alternative interpretation had to be considered.

\section{EXPERIMENT 2}

The results of Experiment 1 are consistent with the notion that the administration of ondansetron at the time of conditioning will prevent the acquisition of a context aversion induced by $\mathrm{LiCl}$-our experimental subjects, Group $\mathrm{A}+$ Ond, given ondansetron before they experienced the pairing of context $\mathrm{A}$ and $\mathrm{LiCl}$, showed no sign of an aversion to context $A$, consuming sucrose in $A$ as readily as in the nontarget context, $B$. Since, however, all of the subjects in Experiment 1 were tested drug free, these results are also what would be expected if the expression of the context aversion were dependent on the animal's being in the drug state that was experienced at the time of conditioning. By this argument, the result observed for Group A+Ond would be the consequence not of a failure of conditioning but of a failure to express the aversion to context $\mathrm{A}$. We may assume that testing drug free would not have impeded the expression of the aversion for subjects in Group A+Veh, since these subjects had received only an injection of saline prior to conditioning with context A.

Experiment 2 was intended to address this issue. In this experiment, all subjects received initial training in which both context $\mathrm{A}$ and context $\mathrm{B}$ were paired with an injection of $\mathrm{LiCl}$ (see the lower panel of Table 1). The conditioning trials in context $\mathrm{A}$, however, were preceded by an injection of ondansetron, whereas trials in context $B$ were preceded by an injection of the saline vehicle. For the test, all subjects were given access to the sucrose in both context $A$ and context $B$. Half of the subjects received an injection of ondansetron prior to the test in context $A$ and an injection of vehicle prior to the test in context $\mathrm{B}$; for the remaining subjects, this arrangement was reversed so that they received saline prior to the test in context $A$ and ondansetron prior to the test in context B. If the only effect of ondansetron was to prevent or attenuate acquisition of the context aversion, it was to be expected that all animals would consume more sucrose in context $A$ than in context B. But if the results of Experiment 1 reflected a state dependency effect, we might expect the aversion to be evident only in the test conditions that matched the conditions of training; that is, suppression of consumption would be shown by animals tested in $\mathrm{A}$ in the presence of the drug, but would be absent in those animals tested in the presence of the drug in context $\mathrm{B}$.

\section{Method}

The subjects were 48 rats from the same stock and maintained in the same way as those used in Experiment 1 . The experiment was conducted in two replications. The rats used in the first had a mean free-feeding weight of $321 \mathrm{~g}$ (range: $300-350 \mathrm{~g}$ ); those used in the second had a mean free-feeding weight of $488 \mathrm{~g}$ (range: $450-520 \mathrm{~g}$ ). The apparatus and the procedures followed were the same as described for Experiment 1, except where specified otherwise.

The conditioning trials began after the initial phase of water deprivation had been established. They were organized as a 4-day cycle. On the Ist day of conditioning, all subjects received an injection of $\mathrm{LiCl}$ before being placed in one or the other of the experimental contexts. For half of the subjects, this conditioning trial was preceded by an injection of ondansetron; for the other half, it was preceded by an injection of the saline vehicle. The next day was a recovery day in which the subjects remained in their home cages where they received two sessions of free access to water, one for $2 \mathrm{~h}$ in the morning, and the other for $2 \mathrm{~h}$ in the afternoon. On Day 3 , all subjects received a conditioning trial with the context that they had not experienced on Day 1. This was preceded by an injection of the vehicle for those that had been given ondansetron on Day 1, and by ondansetron for those that had been given saline on Day 1. Day 4 was again a recovery day during which the subjects received water in the home cage. The context experienced after the ondansetron injection will be referred to as context $\mathrm{A}$, and that experienced after the vehicle injection as context $B$. For half the subjects, the large cages were used as context $A$ and the smaller cages as $B$; for the remainder, this arrangement was reversed. This 4-day cycle of training was repeated a further three times, so that, at the end of the conditioning phase, all subjects had received, in alternation, four trials with A (the ondansetron-paired context) and four with B (the saline-paired context).

The next 2 days constituted the test phase. Over these days, all subjects received a test session with both context A and context $B$ (one test on each day) in which they were given free access to the sucrose solution in the context for $15 \mathrm{~min}$. For half of the subjects, an injection of ondansetron was administered $15 \mathrm{~min}$ prior to the test in context $A$, and an injection of saline prior to the test with context $B$; for the remaining subjects, this arrangement was reversed so that they received saline prior to the test with context $A$ and ondansetron prior to the test with context $\mathrm{B}$. Within the two groups so formed, half the subjects were tested first with context A and half were tested first with context $B$. 


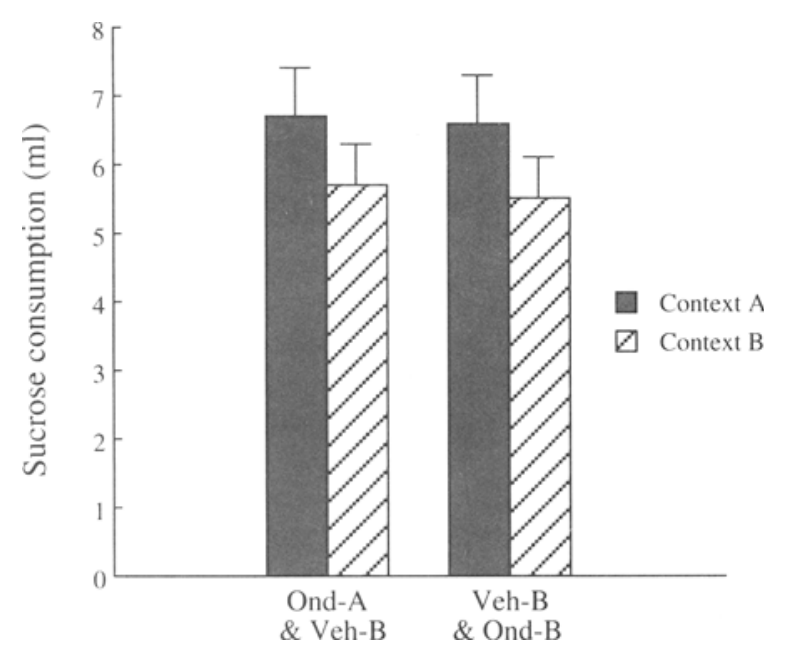

Figure 2. Experiment 2: Group means for sucrose consumption on test in contexts $A$ and $B$. All animals were tested in both contexts. The left-hand bars are for subjects that received an injection of ondansetron before the test in $A$ (Ond-A) and an injection of vehicle before the test in $B$ (Veh-B); the right-hand bars are for animals that received ondansetron before the test in $B$ (Ond-B) and vehicle before the test in $A$ (Veh-A). In previous training, both contexts had been experienced after an injection of $\mathrm{LiCl}$, with an injection of ondansetron being given before trials with context $A$.

\section{Results and Discussion}

The group mean levels of sucrose consumption on the test trials are shown in Figure 2. The left-hand panel of the figure shows the means in each context for the subjects that had received ondansetron prior to the test in context $\mathrm{A}$, and vehicle prior to the test in context $\mathrm{B}$. The means in the right-hand panel are for the subjects that received saline prior to the test in $\mathrm{A}$, and ondansetron prior to the test in B. It is clear from Figure 2 that, for all subjects, the sucrose was consumed more readily when it was presented in context $A$ than when it was presented in context $B$. Whether or not ondansetron was given prior to the test session was without effect. An ANOVA was conducted on the data presented in the figure with the withinsubjects variable of test context (A or B) and the betweensubjects variable of drug state. This revealed only a main effect of test context $[F(1,45)=6.53$; all other $F$ s $<1]$.

The finding that the rats consistently consumed more of the test flavor when it was presented in context $A$ than when it was presented in context $B$ confirms the results of Experiment 1. Giving ondansetron prior to the conditioning trials with a given context attenuates the size of the conditioned aversion, as measured by the rats' unwillingness to consume a novel flavor in that context. The effect is rather smaller than that obtained in Experiment 1, in which animals trained in the presence of ondansetron drank almost twice as much as those trained without the drug (compare Figures 1 and 2). It should be noted, however, that we used rather different initial training procedures in these two experiments: In the first experiment, the animals were given explicit discrimination training between contexts $\mathrm{A}$ and $\mathrm{B}$ (one being associated with $\mathrm{LiCl}$ and one not), whereas in Experiment 2, both contexts were associated with $\mathrm{LiCl}$. If the training procedure used in this experiment was less effective than that used in Experiment 1 in establishing a clear discrimination between the contexts, a smaller effect of the ondansetron would be expected.

The basic effect of ondansetron on context aversion conditioning seen in Experiment 1 can be interpreted as an instance of state dependency, with subjects being unable fully to exhibit the aversion they had acquired when tested in the changed, drug-free state of the test. The present experiment, which showed that the same test result was found regardless of whether or not the subjects were given ondansetron prior to the test, ruled out this possibility. We conclude, therefore, that the administration of the antiemetic during conditioning is effective because it prevents the acquisition of the aversion, presumably because it suppresses the state of nausea that is a critical aspect of the US in this conditioning procedure.

Having said this, it remains to explain why the administration of ondansetron should be apparently quite without effect on test performance. The simplest interpretation of the ability of a conditioned context to control performance is that the context evokes, as a CR, a state of nausea that is essentially the same as the state elicited as a UR by the $\mathrm{LiCl}$ injection given on the conditioning trials. If this were so, however, it would be expected that a drug that suppressed nausea would be effective not only during conditioning, but also on the test (where it would suppress the conditioned state of nausea, just as it suppressed the state directly evoked by an emetic treatment during conditioning). Our failure to find a test effect means that the simple interpretation must be complicated in some way. We have a number of possibilities to suggest (and at this stage we have no way of knowing which, if any, is correct).

First, it is possible that we are wrong in our basic assumption that the $\mathrm{CR}$ in this procedure is conditioned nausea. Although, as our results show, it is necessary for the US to evoke the state of nausea for conditioning to occur, we are not compelled to adopt the assumption that the CR is this same state. Contextual cues might, for instance, acquire the power to evoke the anticipation of nausea - a state that may be unpleasant (and capable of suppressing sucrose consumption) but which is not nausea itself and is thus not susceptible to the effects of antiemetics. Second, it is possible that the context comes to evoke a conditioned state of nausea, but that this is just one of the components of a complex CR and that one of the other components (e.g., a conditioned enhancement of the neophobic reaction) is what is measured in our procedure. If so, a treatment that suppresses (conditioned) nausea need not influence the $\mathrm{CR}$ being assessed. Third, it is possible that the context evokes nausea just as the $\mathrm{LiCl}$ injection does, but that the conditioned and unconditioned states follow differing time courses. It takes some $15 \mathrm{~min}$ for an injection of $\mathrm{LiCl}$ to have any marked effect on behavior 
(Parker, Hills, \& Jensen, 1984), but the effect on the rat of being placed in a conditioned context may well be immediate. An injection of ondansetron that is timed so as to attenuate the effects of the injection would not necessarily be effective in attenuating the response governed by the contextual cues. And finally, it should be acknowledged that the experimental procedures used in Experiment 2 may simply have lacked the sensitivity required for detection of an effect of ondansetron at the test stage.

\section{GENERAL DISCUSSION}

In the experiments reported here, rats received an injection of $\mathrm{LiCl}$ before being placed in a distinctive environmental context; an aversion to this context was then revealed in a subsequent test in which the subjects declined to drink a novel sucrose solution when tested in this context. The main finding of these experiments was that the administration of an antiemetic prior to these conditioning trials attenuated the apparent size of this aversion; subjects for whom the drug had been given prior to context- $\mathrm{LiCl}$ pairings consumed more of the sucrose in this context than in a context in which only the saline vehicle had been given prior to conditioning.

This finding is consistent with the suggestion that an important property of the $\mathrm{LiCl}$ injection is that it induces a state of nausea, and that it is primarily this state that functions as the US in our conditioning procedure. Given that the ANV suffered by patients undergoing chemotherapy is taken to reflect conditioning with the clinic as the CS and cytotoxic-drug-induced nausea as the US, this result encourages us to pursue the proposal that our procedure for establishing context aversions in the laboratory might provide a useful parallel to ANV. Less encouraging is the finding of Experiment 2, that the treatment with an antiemetic appears to be without effect on the expression of a context aversion once acquired. A feature of ANV is that the patients report nausea as a response to the (putative) conditioned stimuli and to the extent that this form of nausea (as distinct from PNV itself) is susceptible to treatment by antiemetics, we would hope to find a parallel effect in our animal model of ANV. Direct evidence that antiemetic medication suppresses ANV is, however, hard to find. As Stockhorst, Wiener, Klosterhalfen, Klosterhalfen, Aul, and Steingrüber (1998) point out, there are relatively few studies in which $5-\mathrm{HT}_{3}$ antagonists have been used as antiemetic medication and in which ANV has been recorded, and in these, the prevalence of ANV was not very much less than that seen in recent studies of ANV in which no antiemetic medication was given. But even in cases in which antiemetics appear to have attenuated ANV, we cannot be sure that this was because of a direct effect on the expression of a CR of conditioned nausea - the medication is typically given throughout the course of treatment and thus, by alleviating PNV, will restrict initial acquisition of the association on which ANV is taken to depend. Further work needs to be done, both in the clinic and in the conditioning laboratory, to resolve the question of whether antiemetics can influence the expression of the CR evoked by cues that have been associated with a state of nausea.

In spite of these uncertainties, enough parallels exist between our context conditioning procedure and the clinical phenomenon of ANV to justify the possible use of the former as a model of the latter. The potential usefulness of such a model becomes clear when it is acknowledged that, in spite of the advent of modern antiemetics, the problem of ANV is still of sufficient severity to make it worthwhile to look for nonpharmacological ways of reducing its occurrence. Possible intervention strategies derived from a conditioning perspective include the principle of overshadowing, in which the presence of one stimulus can substantially reduce the conditioning to another with which it is presented in compound at the time of conditioning. Using our conditioning procedure, we have recently been able to demonstrate the reality of the overshadowing effect in context aversion learning-a novel taste presented in the context during conditioning trials with $\mathrm{LiCl}$ will reduce the size of the context aversion that is formed (Symonds \& Hall, 1999). The feasibility of using an overshadowing intervention in the clinic has recently been tested in a pilot study by Stockhorst, Klosterhalfen, and Steingüber (1998)-patients undergoing chemotherapy who consumed a novel juice drink prior to each treatment session showed less tendency to complain of ANV in comparison with a group that received no overshadowing intervention. A second possible intervention emerges from the finding that prior, nonreinforced exposure to a stimulus will retard future conditioning to that stimulus. This latent inhibition effect has been well documented in a range of conditioning preparations. For the case we are considering, application to the problem of ANV would involve exposing the patients to the clinical environment prior to the chemotherapy sessions, a procedure that would be practical only if the effect could be obtained with a relatively short amount of preexposure. Further work with the animal model could therefore be directed at determining what conditions might be effective in producing rapid development of latent inhibition to contextual cues. And the investigation of the interaction of these behavioral interventions with the effects of antiemetic medication should help establish what may be the optimum strategy for the effective management of ANV in the clinical population.

\section{REFERENCES}

ANDREws, P. L. R., RApeport, W. G., \& SANGER, G. J. (1988). Neuropharmacology of emesis induced by anti-cancer therapy. Trends in Pharmacological Sciences, 9, 334-341.

Balleine, B., Garner, C., \& Dickinson, A. (1995). Instrumental outcome devaluation is attenuated by the anti-emetic ondansetron. Quarterly Journal of Experimental Psychology, 48B, 235-251.

Best, M. R., Brown, E. R., \& Sowell, M. K. (1984). Taste-mediated potentiation of non-ingestional stimuli in rats. Learning \& Motivation, 15, 244-258. 
Boakes, R. A., Westbrook, R. F., \& Barnes, B. W. (1992). Potentiation by a taste of toxicosis-based context conditioning: Effects of varying the test fluid. Quarterly Journal of Experimental Psychology, 45B, 303-325.

Carey, M. P., \& Burish, T. G. (1988). Etiology and treatment of the psychological side effects associated with cancer chemotherapy: A critical review and discussion. Psychological Bulletin, 104, 307-325.

Chaffee, B. J., \& Tankanow, R. M. (1991). Ondansetron-the first of a new class of antiemetic agents. Clinical Pharmacy, 10, 430-446.

Coll, J. D., Hankins, W. G., Jenden, D. J., \& Garcia, J. (1978). The attenuation of a specific cue-to-consequence association by antiemetic agents. Psychopharmacology, 56, 21-25.

DomJan, M. (1977). Selective suppression of drinking during a limited period following aversive drug treatment in rats. Journal of Experimental Psychology: Animal Behavior Processes, 3, 66-76.

Garcia, J., Hankins, W. G., \& Rusiniak, K. W. (1974). Behavioral regulation of the milieu interne in man and rat. Science, 185, 824-831.

Goudie, A. J., Stolerman, I. P., Demellweek, C., \& D’Mello, G. D. (1982). Does conditioned nausea mediate drug-induced conditioned taste aversion? Psychopharmacology, 78, 277-281.

HALl, G. (1997). Context aversion, Pavlovian conditioning, and the psychological side effects of chemotherapy. European Psychologist, 2, 118-124.

Higgins, G. A., Kilpatrick, G. J., Bunce, K. T., \& Tyers, M. B. (1989). $5-\mathrm{HT}_{3}$ receptor antagonists injected into the area postrema inhibit cisplatin-induced emesis in the ferret. British Journal of Pharmacology, 97, 247-255.

MCAllister, K. H. M., \& Pratt, J. A. (1998). GR205171 blocks apomorphine and amphetamine-induced conditioned taste aversions. European Journal of Pharmacology, 353, 141-148.

Mele, P. C., McDonough, J. R., Mclean, D. B., \& O'Halloran, K. P. (1992). Cisplatin-induced conditioned taste aversion: Attenuation by dexamethasone but not zacopride or GR38032F. European Journal of Pharmacology, 218, 229-236.

PARKER, L. A. (1998). Emetic drugs produce conditioned rejection re- actions in the taste reactivity test. Journal of Psychophysiology, 12(Suppl. 1), 3-13.

Parker, L. A., Hills, K., \& Jensen, K. (1984). Behavioral CRs elicited by a lithium- or an amphetamine-paired contextual test chamber. $A n$ imal Learning \& Behavior, 12, 307-315.

Rodríguez, M., LóPEz, M., Symonds, M., \& HALL, G. (1999). Backward conditioning of a context aversion in rats with lithium-induced nausea as the unconditioned stimulus. Manuscript submitted for publication.

RudD, J. A., Ngan, M. P., \& WAI, M. K. (1998). 5-HT3 receptors are not involved in conditioned taste aversions induced by 5-hydroxytryptamine, ipecacuanha or cisplatin. European Journal of Pharmacology, 352, 143-149.

Stockhorst, U., Klosterhalfen, S., Klosterhalfen, W., WinkelMANN, M., \& STEINGRÜBER H.-J. (1993). Anticipatory nausea in cancer patients receiving chemotherapy: Classical conditioning etiology and therapeutical implications. Integrative Physiological \& Behavioral Science, 28, 177-181.

StockhORST, U., Klosterhalfen, S., \& Steingrüber, H.-J. (1998). Conditioned nausea and further side effects in cancer chemotherapy: A review. Journal of Psychophysiology, 12(Suppl. 1), 14-33.

Stockhorst, U., Wiener, J. A., Klosterhalfen, S., Klosterhalfen, W., AUl, C., \& Steingrüber, H.-J. ( 1998). Effects of overshadowing on conditioned nausea in cancer patients: An experimental study. Physiology \& Behavior, 64, 743-753.

SymONDS, M., \& HALL, G. (1997). Contextual conditioning with lithium-induced nausea as the US: Evidence from a blocking procedure. Learning \& Motivation, 28, 200-215.

SYMONDS, M., \& HALL, G. (1999). Overshadowing not potentiation of illness-based contextual conditioning by a novel taste. Animal Learning \& Behavior, 27, 379-390.

(Manuscript received August 16, 1999; revision accepted for publication October 28, 1999.) 